Revistade
Economild
Contemporâned

\title{
UMA ANÁLISE DA DISTRIBUIÇÃO DO PIB PER CAPITA ENTRE MULHERES E HOMENS NO BRASIL, 1991-2015
}

\author{
Hildete Pereira de Melo ${ }^{a}$ \\ Lucilene Morandi ${ }^{b}$ \\ aProfessora Associada da Faculdade de Economia da Universidade Federal Fluminense (UFF). \\ Niterói, Rio RJ, Brasil. ORCID: http://orcid.org/0000-0002-3943-6229.

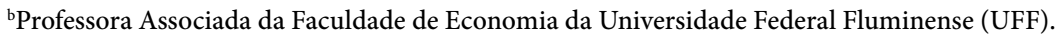 \\ Niterói, RJ, Brasil. ORCID: http://orcid.org/0000-0002-9701-7890. \\ Recebido em 16 outubro 2018 \\ Aprovado em 31 agosto 2020
}

RESUMO: A invisibilidade do trabalho das mulheres é um dos temas mais antigos trazido pelos feminismos para as ciências sociais e é referido como uma tentativa de reinterpretar os conceitos de trabalho remunerado/não remunerado. Em geral, as mulheres participam desigualmente do mercado de trabalho. Os dados mostram que, na média, as mulheres recebem rendimentos mais baixos que os homens, ocupam menos cargos de gerência, têm taxas de rotatividade mais altas no mercado de trabalho, estão concentradas em apenas alguns setores industriais e estão alocadas majoritariamente nos setores de serviços e informal. Ao mesmo tempo, elas são as maiores responsáveis pelas tarefas de cuidados relativos à reprodução da vida, definidas pela divisão sexual do trabalho, uma convenção social e cultural que influencia o acesso e as oportunidades de ascensão no mundo do trabalho. Diante dessa realidade, este estudo visa estimar o diferencial do rendimento per capita feminino em relação ao masculino no Brasil para os anos 1991 e 2000-2015. A contribuição deste artigo está em revelar que as mulheres brasileiras aumentaram e melhoraram sua participação no mercado de trabalho,

Correspondência para: Lucilene Morandi

Contato: lmorandi@id.uff.br 
conseguindo aumentar seu rendimento no período. Mas, apesar de apresentarem escolaridade média superior à dos homens, ainda têm renda per capita de pouco mais de $50 \%$ da renda per capita dos homens. Isso mostra que essa desigualdade vai além da possível justificativa de diferença de qualificação.

PALAVRAS-CHAVE: PIB; PIB per capita feminino; rendimento per capita; macroeconomia de gênero.

CLASSIFICAÇÃO JEL: E0; E2; E6; H0; J0. 


\title{
PER CAPITA GDP: ANALYSIS OF ITS DISTRIBUTION BETWEEN WOMEN AND MEN IN BRAZIL, 1991-2015
}

\begin{abstract}
The issue of the invisibility of women's work is one of the oldest themes brought by feminism to the social sciences and is referred to as an attempt to reinterpret the concepts of paid/unpaid work. In general, women participate unequally in the labor market. The data show that women, on average, receive lower incomes than men, occupy fewer management positions, have higher turnover rates in the labor market, are concentrated in only a few industrial sectors, and are mainly allocated to the services and informal sectors. At the same time, they are mainly responsible for the care tasks related to the reproduction of life, defined by the sexual division of labor, a social and cultural convention that influences access and opportunities for advancing in work environments. Given this reality, this study estimated the difference in per capita income for women compared to men in Brazil for the years 1991 and 2000-2015. The results show that Brazilian women increased and improved their participation in the labor market, managing to increase their income in the period. However, despite having an average schooling higher than that of men, they still have a per capita income of just over $50 \%$ of men's per capita income. This shows that this inequality goes beyond the possible justification of qualification difference.
\end{abstract}

KEYWORDS: GDP; female per capita GDP; per capita income; gender and macroeconomics. 


\section{INTRODUÇÃO'}

O campo de estudos das relações de gênero e dos feminismos desenvolve-se no Brasil desde o início dos anos 1980, resultante tanto do fortalecimento dos movimentos feministas internacionais como dos nacionais. No Brasil, feministas foram para a rua, a partir de 1975, respaldadas pela decisão da Organização das Nações Unidas (ONU) de realizar a I Conferência Internacional da Mulher na cidade do México. Na sequência, as mulheres brasileiras desfraldaram as bandeiras pela volta da democracia e pela igualdade entre os sexos. Assim, a novidade desses últimos quarenta anos foi o avanço da produção acadêmica feminista no mundo e a emergência de novos fundamentos teóricos para interpretar a histórica discriminação das mulheres. Nesta segunda década do século XXI, vive-se um terceiro momento de grande turbulência no campo das relações de gênero e raça, com a postura aguerrida das mulheres no mundo para denunciar as discriminações e desigualdades que as afligem secularmente.

As relações de gênero são o fio condutor que este trabalho utiliza para trafegar entre os cânones estabelecidos pela macroeconomia numa análise da produção agregada. O Produto Interno Bruto (PIB), o mais significativo indicador da produção, é um instrumento quantitativo de dupla natureza entre o saber e poder. Seja por ser "instrumento de conhecimento", construído por métodos científicos, seja por ser "dispositivo de poder", porque revela as relações de poder existentes na sociedade. Ao ignorar, no seu cálculo, o trabalho não remunerado (cuidados e afazeres domésticos) prestado majoritariamente pelas mulheres, exprime a supremacia masculina nas relações de gênero geradas na construção do saber científico. As estatísticas não são neutras e respondem às condições econômicas, políticas e sociais prevalentes no momento de sua definição (AMOSSÉ, 2019; MELO; THOMÉ, 2018).

O caráter exploratório deste estudo não permitiu incorporar a variável raça/cor na sua análise pelas enormes dificuldades metodológicas, embora reconheçamos que a discriminação relativa à raça/cor seja um componente significativo nas explicações de porque o Brasil é tão desigual e tem uma das maiores concentrações de renda do mundo (SOUZA, 2018).

O conceito de relações de gênero é uma construção histórica e social do feminino e do masculino, que interpreta as relações sociais que se estabelecem entre os sexos e

\footnotetext{
Versão mais reduzida e preliminar desse trabalho foi apresentada no I Congreso Internacional Políticas Publicas en Defensa de la Inclusión, la Diversidad y el Género (GIR), Salamanca (Espanha), 16 a 19 de julho de 2018. Esta versão incorpora as sugestões desse debate.
} 
vividas na sociedade mundial com forte assimetria. ${ }^{2}$ Assim, a perspectiva de gênero no estudo das relações socioeconômicas trata da emergência de uma forma mais consistente de analisar os papéis exercidos pelas mulheres e homens na sociedade, apreendendo as desigualdades e analisando, como um de seus componentes centrais, a assimetria de poder. Isso porque a ideologia da natureza feminina criou uma cortina de fumaça que obscureceu as formas de viver das mulheres. A rigor, na produção acadêmica, as mulheres apareciam e ainda aparecem apenas como uma categoria estatística. Em geral, as mulheres recebem salários mais baixos que os homens, apresentam taxas de rotatividade mais altas nos seus respectivos trabalhos, atuam mais comumente nos setores de serviços e informal e, na indústria, estão concentradas apenas em alguns ramos manufatureiros. Essa diferença também ocorre quando se analisam os dados do mercado de trabalho com corte de sexo e cor/raça. Segundo dados do IBGE, no Brasil, os maiores rendimentos são de homens brancos, em seguida os de mulheres brancas, depois homens pretos e pardos e por último os das mulheres pretas e pardas. ${ }^{3} \mathrm{Ou}$ seja, analisando cada grupo racial em separado, prevalece o fato de os homens receberem mais que as mulheres. Mas a ciência, na perspectiva das mulheres, deveria ir além disso e os feminismos seriam "uma ideologia política ou uma perspectiva crítica do conhecimento que, superando os preconceitos de gênero nas relações sociais teria um lugar importante na revisão de ciências que omitem as mulheres (AGUIAR, 1997, p. 9-10).

Os trabalhos acadêmicos sobre a condição feminina referem-se a temas como mercado de trabalho, educação, saúde reprodutiva, participação política e família. Uma das temáticas mais recorrentes é a da invisibilidade do trabalho da mulher, numa discussão, sobretudo com a economia, sobre a desvalorização do trabalho doméstico e de cuidados. Esse é um dos temas mais antigos trazidos pelo feminismo para as ciências sociais e está referenciado a uma tentativa de reinterpretar os conceitos de trabalho doméstico, no qual a distinção trabalho remunerado/não remunerado é a ponta do iceberg para a denúncia da questão da inferioridade feminina.

A questão da invisibilidade do trabalho feminino permanece obscura porque, tanto na visão liberal como na marxista, a subordinação feminina é explicada por sua exclusão do mundo mercantil e esta se deve a razões culturais. Feministas marxistas argumentam que as mulheres na esfera doméstica são exploradas por seus companheiros, sejam eles trabalhadores ou capitalistas, pois os afazeres domésticos são o tipo mais comum de

2 O conceito de gênero é um dos principais instrumentos teóricos utilizado pela produção acadêmica feminista. Foi definido pela historiadora Joan Scott (1990) como a organização social da diferença.

3 Segundo dados da PNAD-C (IBGE, 2020), o rendimento médio das mulheres, em 2019, era de 77,7\% do rendimento médio dos homens e as pessoas de cor branca tinham rendimento $29,9 \%$ superior à média nacional, enquanto as pessoas pretas e pardas tinha, respectivamente, rendimento 25,5 e 27,5\% inferior a essa média. 
trabalho não remunerado (MACKINNON, 2016). Não há equivalência na “troca” entre capital e trabalho, apenas uma igualdade de estatuto jurídico em sua relação contratual. Não é uma relação de troca entre portadores de mercadorias, e sim uma relação desigual de poder garantida e regulada pelo Estado (MELO; SERRANO, 1997).

As teorias neoclássica e marxista silenciam sobre a desigualdade dentro de casa, a desigualdade que envolve o trabalho não remunerado de afazeres domésticos e cuidados. A teoria neoclássica restringe sua análise às relações de mercado, o que a impossibilita explicar conflitos ou desigualdades, dado que o mercado pressupõe relações de liberdade de escolha e independência, levando em conta os preços e as preferências individuais. Portanto, a decisão entre trabalho remunerado e não remunerado é também uma escolha ótima e, presume-se, seja a maximização da utilidade conjunta dos membros da família. ${ }^{4}$ A teoria marxista, por sua vez, estende sua análise do modo de produção capitalista às famílias e agrega as pessoas da família (homens, mulheres, crianças) de forma indiferenciada em classes sociais, supondo ser suficiente a sua análise crítica ao capitalismo (FOLBRE, 1986).

A teoria econômica, nas suas diferentes vertentes, limita-se a examinar essa questão sob a ótica das relações de trabalho remunerado, sem levar em conta o trabalho não remunerado realizado no interior dos domicílios, relacionado aos cuidados com a família. Em conformidade com a teoria neoclássica, uma de suas vertentes, representada por Gary Becker, incluiu a família, o casamento e o divórcio na análise econômica, mas limitou-se a explicar por que as pessoas casam, com quem e por que se separam. ${ }^{5}$ Deixando de lado o aspecto de essa análise ser importante, ela não contribui para explicar a desigualdade econômica entre os sexos, seja relativa aos rendimentos ou à concorrência no mercado de trabalho, e nem por que essa situação persiste (BECKER, 1988, p. 10). Para a teoria econômica, a concorrência intra e intercapitalistas e trabalhadores em uma sociedade mercantil ignora sexo e raça/cor. Leva em conta apenas competência e capacidade. Mas, na realidade, as diferenças de sexo e raça/cor consistem em um dos fatores de clivagem dessa concorrência, funcionando como álibi para a discriminação. As relações capitalistas em geral tendem a reproduzir as condições culturais do organismo social, que, no entanto, estão definidas pela dinâmica da acumulação capitalista.

O ocultamento das tarefas domésticas nas estatísticas oficiais de produção e consumo, como algo que foge ao escopo da teoria econômica por não resultar de relações mercantis de compra/venda, foi tratado pelo pensamento feminista como a construção da imagem

4 Ver Folbre (1986) para maior discussão sobre a inexatidão do conceito de "utilidade conjunta".

5 Essas pesquisas foram a razão para que a Academia Real de Ciências da Suécia concedesse, em 1992, o Prêmio Nobel de Economia a esse economista. 
partida da mulher, julgada cidadã de segunda categoria. Essas tarefas, que antes eram organizadas por meio de relações de parentesco e inseparáveis em relação a sexo e classe, são tratadas separadamente e mantêm uma íntima relação com a situação de inferioridade da mulher no mundo atual. ${ }^{6}$

Dessa forma, este trabalho tem como objetivo o desafio de apresentar como a renda per capita está desigualmente distribuída entre homens e mulheres e como essa desigualdade persiste ao longo do tempo. O estudo da ONU (UN, 2016) mostra que, se eliminássemos a diferença de rendimentos entre homens e mulheres no mercado de trabalho, a renda das mulheres aumentaria em pelo menos $30 \%$. Isso teria impacto direto também sobre as estimativas do PIB e, portanto, de renda nacional. Atualmente, o rendimento das mulheres menor que o dos homens ocorre mesmo quando elas têm a mesma qualificação e ocupam postos de trabalho semelhantes aos deles, mesmo considerando que as mulheres apresentam, desde 1991, um grau de escolaridade médio superior ao dos homens. Dados da última PNAD Anual 2015 (IBGE, 2015) mostram que $21,7 \%$ das mulheres de 18 a 24 anos estão na universidade, enquanto para os homens essa taxa era de 15,4\%. A superioridade educacional, contudo, não quebra a cultura da desigualdade de gênero e de raça/cor, nem tampouco a hierarquia predominante entre mulheres brancas e pretas/pardas (MELO; THOMÉ, 2018; MORANDI; MELO, 2019).

Os resultados aqui apresentados revelam que as mulheres brasileiras aumentaram e melhoraram sua participação no mercado de trabalho, conseguindo aumentar seu rendimento nesse período. Mas, apesar de terem escolaridade média superior à dos homens, sua renda per capita é pouco mais que $50 \%$ da renda per capita dos homens, o que mostra que a desigualdade de gênero no mercado de trabalho vai além da possível justificativa de diferença de qualificação.

Com essas preocupações, este estudo faz estimações para a distribuição do PIB per capita brasileiro entre os sexos nos últimos 25 anos, mostrando como a diferença da renda auferida por homens e mulheres tem se mantido em prejuízo delas, apesar do aumento da participação das mulheres no mercado de trabalho e da redução da diferença de rendimento ao longo desse um quarto de século.

\footnotetext{
6 Segundo Vanderlac (1994, p. 178-179), para Colin Clark (1971) a exclusão do trabalho doméstico das estatísticas oficiais de renda é arbitrária, pois Alfred Marshall (1920), ao dar parecer positivo para a exclusão do trabalho doméstico das estatísticas do produto nacional, reconheceu que havia incoerência nessa omissão.
} 


\section{A DISTRIBUIÇÃO DA RENDA NACIONAL: UMA ANÁLISE DE GÊNERO}

Nos trabalhos de Melo, Considera e Sabbato (2005, 2007 e 2016), os autores levantam a discussão sobre a situação do trabalho familiar dos cuidados e da reprodução da vida num marco analítico da teoria econômica feminista. Esse tema foi tratado pelos economistas clássicos na discussão sobre salários e como custo de reprodução histórica da classe trabalhadora, perspectiva presente também na interpretação de Marx (MELO; CASTILHO, 2009; PICCHIO, 1999). Notem que tanto os clássicos como os marxistas não valoram os trabalhos que as mulheres realizam no interior das suas famílias e estes não são incorporados em seus esquemas analíticos representativos do sistema econômico. Isso se consagrou com a teoria neoclássica, que deslocou o foco analítico da produção para o mercado e separou definitivamente as esferas de produção mercantil e doméstica.

Essa separação explicita-se nas análises macroeconômicas relativas às Contas Nacionais por não contabilizarem o trabalho no interior das famílias como possuindo valor econômico, por essas atividades não serem permeadas por trocas monetárias (MELO; CASTILHO, 2009; MICHEL, 1977; VANDERLAC, 1994). Este artigo, preocupado com essa ausência, tenta estabelecer uma conexão entre os trabalhos realizados majoritariamente pelas mulheres no ambiente doméstico e a Contabilidade Nacional. Para tal, propõe uma análise exploratória e ousada de um importante indicador para a análise da distribuição da riqueza nacional, o PIB per capita. A literatura econômica tradicionalmente não apresenta, também por dificuldades metodológicas, os cálculos do PIB per capita discriminado por sexo ou por raça/cor. Assim, não é possível atualmente dimensionar, a partir dele, as diferenças de rendimento entre homens e mulheres e as diferentes raças/cores.

A repercussão do movimento feminista levou à formulação do conceito de gênero, incorporado pelos vários campos do saber, como uma teia de relações de poder que se estabelecem entre as mulheres e os homens (SCOTT, 1990). Na realidade, deve-se repensar a família não mais como um conjunto homogêneo, mas uma situação de convivência entre indivíduos de sexos diferentes, que realizam atividades produtivas e reprodutivas, compartilhando um projeto de sobrevivência. O problema é que o desconhecimento da especificidade da contribuição das mulheres leva à subestimação das práticas por elas exercidas no espaço familiar e no produtivo, acentuando a ideia do subemprego feminino. A invisibilidade que cerca o estudo das diferenças das relações de gênero fortalece a reprodução das desigualdades em relação às possibilidades e às oportunidades de emprego que podem ser oferecidas às mulheres pelo desenvolvimento (WALKER, 1977).

Ester Boserup (1970), no seu trabalho pioneiro, definiu a divisão sexual do trabalho como um elemento de base na divisão do trabalho. A autora apontou que o cálculo do produto nacional, ao não contabilizar os valores da produção e dos serviços de subsistência, subestima as atividades realizadas pelas mulheres e suas contribuições 
ao bem-estar socioeconômico por não dar a devida importância a essas atividades. As críticas realizadas pelas acadêmicas feministas, no final dos anos 1970, ajudaram a ampliar a discussão sobre as formas de valorizar o papel das mulheres nas duas instâncias sociais: a produção e a reprodução. ${ }^{7}$

Esse enfoque mais amplo evidencia que a plena participação das mulheres na sociedade pode ser visualizada através da eliminação das limitações que as marginalizam ou as tornam invisíveis, seja nas atividades domésticas, seja nas atividades públicas e produtivas. O trabalho de Ann Oakley (1974), ao explicitar a relação do trabalho do homem com o trabalho produtor de mercadorias, e o da mulher com a casa, conclui que o termo dona de casa não pode ser sinônimo de esposa e mãe, mas de trabalhadora doméstica sem remuneração. Isso colocou, naquela década, mais lenha na fogueira da rebelião feminina ao não aceitar mais os velhos estereótipos do papel feminino e desmascarar o trabalho não remunerado.

A perspectiva de gênero possibilita uma avaliação mais rica sobre a quantidade e a qualidade das mudanças que as mulheres vivenciaram nas últimas décadas, devido às transformações acontecidas em todas as atividades econômicas. Esse reconhecimento implica em reavaliar a metodologia de cálculo das Contas Nacionais, que vela o trabalho doméstico e, dessa forma, não reconhece sua enorme importância para o bem-estar da sociedade. Para culminar, a IV Conferência Mundial sobre a Mulher, realizada em Pequim (China) em 1995, colocou nas suas recomendações a necessidade de se incorporar a contribuição do trabalho não remunerado, realizado majoritariamente por mulheres, numa conta satélite, um exercício contábil que permite realçar o produto gerado pelo trabalho não remunerado, ignorado pelas estimativas do PIB. As contas satélites "são uma extensão do Sistema de Contas Nacionais. Elas permitem a elaboração de análises sobre o perfil e a evolução de um determinado setor, de forma comparável ao total da economia medido pelas Contas Nacionais" (IBGE, 2017, p. 7).

\section{A PERSPECTIVA DE GÊNERO E O PRODUTO INTERNO BRUTO PER CAPITA}

Para as análises macroeconômicas, as Contas Nacionais são a fonte mais segura e mais abrangente para avaliar o desempenho econômico de uma economia, por manterem regularidade no tempo e disponibilizarem extensas séries de dados. Através de modelos teóricos, é possível analisar e interpretar o comportamento de variáveis macroeconômicas, como renda, emprego, nível geral de preços e de rendimentos, consumo, investimento,

\footnotetext{
7 Sobre o tema, ver Hakiki-Talahite (1984).
} 
importações e exportações. Ou seja, através das Contas Nacionais é possível avaliar a atividade econômica num determinado período em seus múltiplos aspectos.

O Sistema de Contas Nacionais (SCN) é "uma ferramenta com um objetivo bem estabelecido: a partir de um marco estrutural teórico, ele apresenta recomendações de como obter os dados para quantificar esse marco" (FEIJÓ; RAMOS, 2008, p. 8) e, portanto, é um sistema que evolui junto com a teoria econômica, aprimorando e renovando conceitos. Ao longo dos anos, os avanços tecnológicos e estatísticos permitiram melhores formas de coleta e de tratamento de dados, propiciando representação mais adequada das atividades econômicas. No Brasil, o SCN, de responsabilidade do IBGE, segue as recomendações da Organização das Nações Unidas (ONU), desenvolvidas em conjunto com outros organismos, como o Fundo Monetário Internacional (FMI), a Comissão das Comunidades Europeias, a Organização para a Cooperação e Desenvolvimento Econômico (OCDE) e o Banco Mundial, explicitadas no Manual das Contas Nacionais da ONU, o System of National Accounts de 1993, incorporando as atualizações já realizadas até 2008 ou SNA 2008 (IBGE, 2016).

A estrutura do SCN visa integrar os vários sistemas contábeis de representação da atividade econômica, como o balanço de pagamentos, as contas monetárias e financeiras e contas fiscais, de onde são derivados os principais agregados econômicos. Essas contas descrevem os eventos econômicos básicos, como produção, consumo, acumulação e riqueza, e são compostas por três conjuntos de contas: as contas correntes, que mostram a produção, distribuição e redistribuição da renda; as contas de acumulação, que apresentam as alterações no patrimônio líquido, compostas pela conta de capital e pela conta financeira; e as contas de patrimônio financeiro, que registram os estoques e as variação dos ativos, passivos e patrimônio líquido.

O PIB é o principal indicador econômico gerado pelas Contas Nacionais e contabiliza o valor total da produção mercantil de bens e serviços, permitindo a análise de sua evolução ao longo do tempo. Como a renda não é igualmente distribuída entre as pessoas e nem entre os sexos e raças/cores, a metodologia de cálculo do PIB gera um indicador genérico da atividade econômica. Esse indicador é também uma estatística básica para a análise da economia, definição de políticas econômicas, bem como para decisões de investimentos empresariais. Usa-se também o cálculo do PIB para avaliar a renda média da sociedade (PIB per capita = valor do PIB dividido pela população), comumente utilizado como uma medida de capacidade de geração de riqueza pelo país. Essa medida, no entanto, mostra apenas a renda média caso essa fosse igualmente distribuída na população. Nem o PIB nem o PIB per capita são indicadores que permitem a análise da distribuição da renda segundo o sexo ou raça/cor. As estatísticas, no entanto, mostram que existem diferenças importantes dos rendimentos quando se incluem esses quesitos. O que se observa é que a Economia, a Sociologia e a Política esquecem o autêntico 
objetivo das pessoas: a vida, o bem-estar e a reprodução. A utilização do conceito divisão sexual do trabalho, consolidado desde os anos 1970 na perspectiva feminista das ciências econômica e sociais, mostra que as atividades realizadas principalmente pelas mulheres na família estão ausentes das Contas Nacionais, não sendo contabilizadas porque não são atividades mercantis. No entanto, as várias mudanças metodológicas incorporadas ao SCN já incluem estimativas de atividades não mercantis, como a renda de aluguel relativa ao uso da casa própria.

A discussão sobre as estatísticas econômicas de gênero destaca sua importância para a aplicação de políticas públicas mais coerentes com a realidade. As estatísticas, tanto sobre renda quanto sobre emprego, com corte de gênero, cor/raça e região geográfica, permitem que as análises sobre distribuição de renda e taxa de desemprego, por exemplo, sejam mais acuradas e as propostas de políticas públicas mais coerentes com a economia em análise.

Assim como o valor agregado do PIB não é suficiente para a análise macroeconômica, as estatísticas formadoras do PIB, como definidas na atualidade no Brasil, não são satisfatórias em alguns aspectos e requerem avanços metodológicos. Há uma necessidade hoje que algumas dessas estatísticas permitam estudos macroeconômicos com corte de gênero e cor/raça, visto que os dados mostram que há diferenças importantes entre rendimentos e oportunidades no mercado de trabalho quando essas características são consideradas. Essa preocupação, como comentado anteriormente, foi incluída nas diretrizes da ONU a serem seguidas pelos países que publicam o SCN próprio, e já são realizadas por alguns países na América Latina e no mundo.

Aparentemente, a metodologia das Contas Nacionais, na forma como está estruturada, contribui para que seja feita uma associação linear da atividade masculina com produção mercantil e da feminina com atividade familiar doméstica. $O$ significado dessa associação é a percepção da invisibilidade do trabalho das mulheres e a desvalorização do seu lugar na sociedade. As pessoas que exercem afazeres domésticos e cuidados, as donas de casa, sequer são consideradas como força de trabalho (PEA) e, portanto, nem são consideradas na contabilização da taxa de desemprego. Elas são classificadas como população inativa. Curiosamente, se estiverem exercendo, mesmo que sem remuneração, atividades em um empreendimento familiar, são tratadas como população ocupada. Segundo o SNA (2007), no seu capítulo VI sobre a Conta de Produção, os afazeres domésticos são excluídos do cálculo do PIB pelo fato de serem produtos de uso exclusivo doméstico das famílias, e não podem, como a produção de bens agrícolas ou industriais para uso próprio, serem destinados alternativamente ao mercado (MELO; CONSIDERA; SABBATO, 2007). Julga-se que a produção familiar para uso próprio não cumpre as exigências de mercado e, portanto, não exprime a realidade do mercado capitalista. 
A efervescência do pensamento feminista provocou várias tentativas de mensuração do tempo do trabalho não remunerado (afazeres domésticos e cuidados) e sua incorporação ao PIB. Na França, Meron (2016) cita os trabalhos de Ana Chadeau e Annie Fouquer, de 1981, e posteriormente o estudo de Delphine Roy, de 2012, que propuseram formas para imputar valor ao tempo do trabalho não remunerado realizado pelas pessoas na sociedade francesa. Essas propostas apresentavam um conjunto de métodos que imputavam desde uma remuneração mínima que alguém receberia para realizar aquele trabalho (salário-mínimo líquido), ou o preço mínimo necessário para alguém executar esse trabalho ou o custo médio por hora de cada profissão da pessoa que realiza essas tarefas. Esses diversos métodos encontraram valores que variavam de $13 \%$ a $71 \%$ do PIB, concluindo que o valor do trabalho doméstico não remunerado, em média, nas definições intermediárias pode oscilar entre 15\% e 30\% do PIB (MERON, 2016, p. 132-133).

No Brasil, desde 2001, a Pesquisa Nacional por Amostra de Domicílios (PNADAnual) divulga o número de horas despendido pela população na execução de afazeres domésticos ou trabalho não remunerado. A introdução dessa questão no corpo do questionário permite uma estimação, mesmo que precária, do valor econômico do trabalho realizado no interior do domicílio. Graças à introdução dessa questão nos questionários da pesquisa, é possível ter informações para fazer uma mensuração dos afazeres domésticos, nas pesquisas relativas ao mundo do trabalho, coerente com o SCN.

Os trabalhos de Melo, Considera e Sabbato (2005, 2007 e 2016) mostraram que é possível elaborar um cálculo para mensurar o valor adicionado relativo aos afazeres domésticos, partindo da premissa de valorar o trabalho não remunerado a partir do rendimento médio das trabalhadoras domésticas. ${ }^{8}$ No texto de 2016 , esses autores concluíram que as horas dedicadas pelas mulheres a afazeres domésticos eram duas vezes e meia as horas dedicadas pelos homens, e que o número de mulheres empenhadas em afazeres domésticos era duas vezes superior ao número de homens realizando essas tarefas. Esse trabalho (MELO; CONSIDERA; SABBATO, 2016, p. 181) mostrou que a renda correspondente aos afazeres domésticos realizados pelas mulheres no período de 2001 a 2011, se contabilizada no PIB, equivaleria a uma renda duas vezes e meia maior que a renda correspondente aos afazeres domésticos realizados pelos homens no mesmo período. Pode-se afirmar que nesses dez anos, escondidas em seus lares,

\footnotetext{
8 São utilizados três métodos: i) renda semanal com trabalho doméstico remunerado (PNAD) multiplicada por 52 semanas; ii) renda semanal com trabalho doméstico remunerado da PNAD em salários-mínimos do mês de setembro, multiplicado pelo total de salários-mínimos do ano respectivo; e iii) renda semanal com trabalho doméstico remunerado, calculada com base na variação do rendimento médio mensal das pessoas ocupadas em trabalho doméstico remunerado segundo a PME/IBGE (MELO; CONSIDERA; SABBATO, 2007, p. 450).
} 
as mulheres brasileiras geraram o equivalente a um PIB anual (2016, p. 181). Ou seja, as mulheres nessa década, ao cuidarem dos maridos, filhos, doentes, idosos, produziram uma quantidade de bens e serviços para nossa sociedade que não foi contabilizada, nem teve seu valor reconhecido. Por conseguinte, os afazeres domésticos e os cuidados foram ignorados na representação da produção social de riqueza. A metodologia elaborada pelos autores concluiu que o PIB brasileiro aumentaria cerca de $13 \%$, no período considerado, caso se valorasse o trabalho não remunerado executado pelas mulheres a serviço de suas próprias famílias (MELO, CONSIDERA e SABBATO, 2016, p. 181-185). Prosseguindo nessa vertente metodológica, este texto propõe uma abordagem para estimar o tradicional PIB per capita nacional com o corte de gênero.

\section{ESTIMAÇÃO DO PIB PER CAPITA COM CORTE DE GÊNERO}

Este trabalho usa como referência a metodologia desenvolvida pelo professor João Lizardo de Araújo (COPPE/UFRJ) em conjunto com Hildete Pereira de Melo, em 2004, para estimação do PIB per capita com corte de gênero. A hipótese utilizada no cálculo, denominada por Araújo como heroica, considera que os rendimentos entre homens e mulheres (variável não observável) se distribuem proporcionalmente da mesma forma que os rendimentos auferidos no trabalho principal pelo sexo feminino e masculino. Esses dados estão disponíveis nas estatísticas censitárias e nas pesquisas domiciliares do IBGE. Essa reflexão estimulou posteriormente a publicação dos trabalhos de Melo, Considera e Sabbato $(2005,2007)$, que desenvolveram uma pesquisa para valorar os afazeres domésticos no cálculo do PIB brasileiro.

Segundo a metodologia de Araújo e Melo (2004), para o cálculo do PIB per capita por gênero são necessárias estimativas de algumas variáveis macroeconômicas, como a participação relativa de homens e mulheres na população economicamente ativa (PEA); o rendimento do trabalho principal das mulheres como proporção do rendimento do trabalho principal dos homens; o PIB; e a população total distribuída entre homens e mulheres. ${ }^{9}$

Definindo a participação feminina na conta salarial, $s f$, como:

\footnotetext{
9 O cálculo aqui apresentado ainda não incorpora o corte de raça/cor por dificuldades metodológicas e escassez de dados. Serão necessários mais desenvolvimentos metodológicos para que se chegue a uma estimativa do PIB per capita condizente com a realidade (ver uma versão preliminar desta pesquisa em MELO; MORANDI; DWECK, 2018).
} 


$$
S_{f}=\frac{\left(w_{f} / w_{m}\right) * e a_{f}}{\left[\left(w_{f} / w_{m}\right) * e a_{f}\right]+e a_{m}}
$$

sendo: $w_{f}$ a massa salarial das mulheres; $w_{m}$ a massa salarial dos homens; $e a_{f}$ a participação da população feminina no total da PEA; e $e a_{m}$ a participação da população masculina no total da PEA.

O PIB per capita feminino, $P I B F_{p c}$, é igual a:

$$
P I B F_{p c}=s_{f} \star\left(P I B / N_{f}\right)
$$

sendo $N_{f}$ a população feminina total; e o PIB total em reais de 2015.

E o PIB per capita masculino, $P I B M_{p c}$, é igual a:

$$
P I B M_{p c}=\left(1-s_{f}\right) *\left(P I B / N_{m}\right)
$$

Foram utilizados os dados de população total, população economicamente ativa

\begin{tabular}{|c|c|c|c|c|c|c|}
\hline Ano & $\begin{array}{c}\text { PIB } \\
\text { (R\$ bilhões 2015) }\end{array}$ & $\begin{array}{c}w_{f} / w_{m} \\
(\%)\end{array}$ & $\begin{array}{l}e a_{f} \\
(\%)\end{array}$ & $\begin{array}{l}e a_{m} \\
(\%)\end{array}$ & $\begin{array}{c}N_{f} \\
\text { (milhóes) }\end{array}$ & $\begin{array}{c}N_{m} \\
\text { (milhões) }\end{array}$ \\
\hline 1991 & $3.092,8$ & 58,0 & 32,5 & 67,5 & 74,3 & 72,5 \\
\hline 2000 & $3.959,4$ & 65,2 & 40,0 & 60,0 & 87,3 & 86,2 \\
\hline 2001 & $4.014,4$ & 69,6 & 41,8 & 58,2 & 88,5 & 87,3 \\
\hline 2002 & $4.137,0$ & 70,2 & 43,8 & 56,2 & 89,8 & 88,5 \\
\hline 2003 & $4.184,2$ & 70,8 & 44,4 & 55,6 & 91,0 & 89,6 \\
\hline 2004 & $4.425,2$ & 71,1 & 44,9 & 55,1 & 92,2 & 90,7 \\
\hline 2005 & $4.566,9$ & 71,2 & 43,7 & 56,3 & 93,4 & 91,8 \\
\hline 2006 & $4.747,9$ & 71,1 & 45,1 & 54,9 & 94,5 & 92,8 \\
\hline 2007 & $5.036,1$ & 70,1 & 45,5 & 54,5 & 95,6 & 93,8 \\
\hline 2008 & $5.292,6$ & 70,8 & 45,7 & 54,3 & 96,7 & 94,8 \\
\hline 2009 & $5.286,0$ & 70,7 & 46,0 & 54,0 & 97,8 & 95,8 \\
\hline 2010 & $5.683,9$ & 72,0 & 44,1 & 55,9 & 98,8 & 96,7 \\
\hline 2011 & $5.909,8$ & 73,3 & 46,1 & 53,9 & 99,8 & 97,6 \\
\hline 2012 & $6.023,3$ & 72,4 & 46,2 & 53,8 & 100,8 & 98,5 \\
\hline 2013 & $6.204,3$ & 73,5 & 46,5 & 53,5 & 101,7 & 99,3 \\
\hline 2014 & $6.235,6$ & 74,2 & 46,5 & 53,4 & 102,6 & 100,2 \\
\hline 2015 & $6.000,5$ & 75,6 & 43,7 & 56,2 & 103,5 & 101,0 \\
\hline
\end{tabular}
(PEA) e PIB publicados pelo IBGE para os respectivos anos (Tabela 1).

Tabela 1 - Valores das principais variáveis, 1991-2015

Fonte: Elaboração e estimativas próprias com base em dados de IBGE e IPEADATA, vários anos. 
Os valores estimados de PIB per capita feminino para o período 1991 e 2000-2015 mostram uma melhora na proporção entre o PIB per capita feminino e o PIB per capita masculino, passando de 42,2\% em 2000 para 57,2\% em 2015 (Tabela 2), com redução da desigualdade entre os montantes de renda apropriados por cada sexo. Apesar disso, também mostra a permanência da desigualdade, com prejuízo dos rendimentos da população feminina. Nessas duas décadas e meia, mesmo com o aumento da participação das mulheres no mercado de trabalho brasileiro, não houve melhoria proporcional dos rendimentos das mulheres. Além disso, os dados do Censo Demográfico Brasileiro (1991) mostram que, pela primeira vez, o nível médio de escolaridade das mulheres foi maior que o dos homens (SOARES; MELO; BANDEIRA, 2014). Todavia, essa vantagem educacional tão pouco promoveu a igualdade dos rendimentos entre os sexos. Destaca-se que, em 1991, o gap entre rendimentos médios de homens e mulheres era bem superior, resultando num PIB per capita feminino igual a apenas $27,2 \%$ do PIB per capita masculino (Tabela 2 e Gráfico 1).

Tabela 2 - Estimação do PIB per capita por sexo, Brasil (em R\$ de 2015)

\begin{tabular}{|c|c|c|c|c|c|}
\hline \multirow[b]{2}{*}{ Ano } & \multicolumn{2}{|c|}{ PIB per capita feminino $\left(P I B F_{p c}\right)$} & \multicolumn{2}{|c|}{ PIB per capita masculino $\left(P I B M_{p c}\right)$} & \multirow{2}{*}{$\frac{P I B F_{p c}}{P I B M_{p c}}(\%)$} \\
\hline & $\begin{array}{c}\text { Valor } \\
\text { estimado }(\mathbf{R} \$)\end{array}$ & $\begin{array}{c}\text { Taxa de } \\
\text { crescimento (\%) }\end{array}$ & $\begin{array}{c}\text { Valor } \\
\text { estimado (R\$) }\end{array}$ & $\begin{array}{c}\text { Taxa de } \\
\text { crescimento (\%) }\end{array}$ & \\
\hline 1991 & $9.081,9$ & - & $33.353,8$ & - & 27,2 \\
\hline 2000 & $13.743,6$ & - & $32.028,7$ & - & 42,2 \\
\hline 2001 & $15.106,3$ & 9,9 & $30.649,5$ & $-4,3$ & 49,3 \\
\hline 2002 & $16.311,1$ & 8,0 & $30.202,9$ & $-1,5$ & 54,0 \\
\hline 2003 & $16.620,8$ & 1,9 & $29.814,7$ & $-1,3$ & 55,7 \\
\hline 2004 & $17.607,4$ & 5,9 & $30.889,3$ & 3,6 & 57,0 \\
\hline 2005 & $17.407,8$ & $-1,1$ & $32.051,9$ & 3,8 & 54,3 \\
\hline 2006 & $18.541,6$ & 6,5 & $32.272,4$ & 0,7 & 57,5 \\
\hline 2007 & $19.552,7$ & 5,4 & $33.744,1$ & 4,6 & 57,9 \\
\hline 2008 & $20.447,4$ & 4,6 & $34.962,6$ & 3,6 & 58,5 \\
\hline 2009 & $20.313,3$ & $-0,7$ & $34.455,1$ & $-1,4$ & 59,0 \\
\hline 2010 & $20.844,3$ & 2,6 & $37.481,1$ & 8,8 & 55,6 \\
\hline 2011 & $22.810,2$ & 9,4 & $37.226,2$ & $-0,7$ & 61,3 \\
\hline 2012 & $22.948,8$ & 0,6 & $37.681,5$ & 1,2 & 60,9 \\
\hline 2013 & $23.792,6$ & 3,7 & $38.100,0$ & 1,1 & 62,4 \\
\hline 2014 & $23.847,6$ & 0,2 & $37.825,9$ & $-0,7$ & 63,0 \\
\hline 2015 & $21.486,6$ & $-9,9$ & $37.410,7$ & $-1,1$ & 57,4 \\
\hline
\end{tabular}

Fonte: Elaboração e estimativas próprias com base em dados de IBGE e IPEADATA. 
A partir dos dados disponíveis de escolaridade e rendimento e os cálculos realizados para o PIB per capita por sexo, pode-se inferir que o aumento da escolaridade feminina se refletiu, de forma contundente, em aumento do rendimento médio das mulheres. Isso fica claro quando se comparam os dados de 2000 em relação a 1991 . A taxa média de crescimento anual nesse intervalo de tempo é de 1,5\%. Por outro lado, pode-se inferir também que o crescimento do rendimento das mulheres, em consequência de seu maior nível de escolaridade, não continuou na mesma proporção nos anos seguintes, nem conseguiu promover a igualdade de rendimento de mulheres e homens (Tabela 2 e Gráfico 1).

\section{Gráfico 1 - PIB per capita feminino / PIB per capita masculino, 1991-2015 (em \%)}

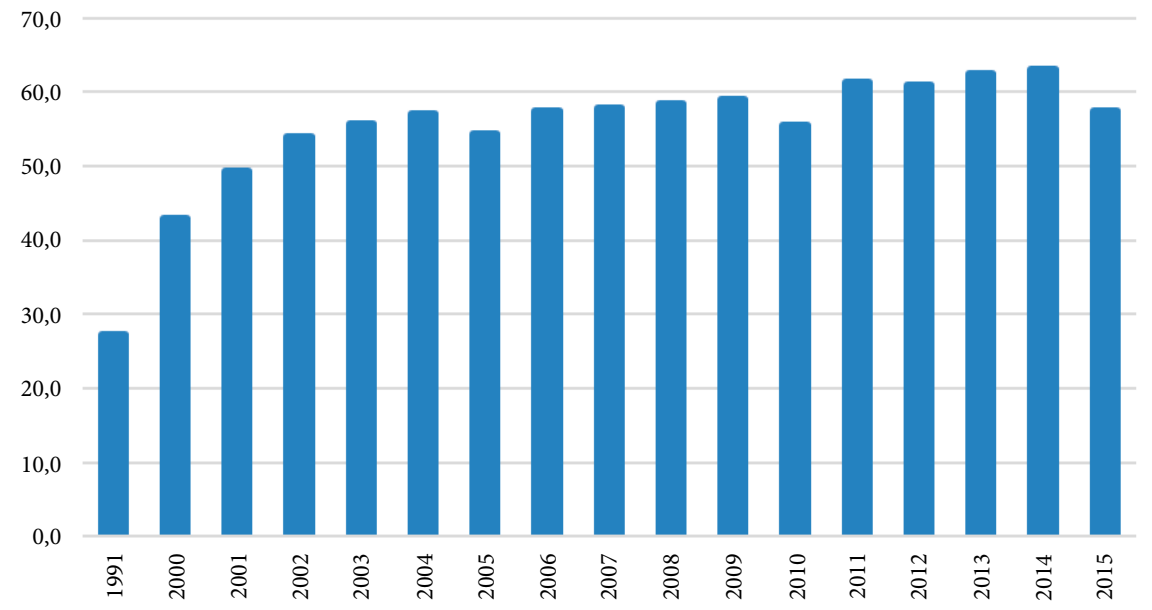

Fonte: Elaboração e estimativas próprias com base em dados de IBGE e IPEADATA, vários anos.

Os anos de 2001 a 2003 apresentam taxa de crescimento negativas para o PIB per capita masculino, enquanto o PIB per capita feminino apresenta taxas positivas no período. Isso implica que as mulheres tiveram ganhos reais de rendimento em relação ao rendimento dos homens nesse período. Mas essa tendência também não se mantém e nos demais anos os dois PIB per capita apresentam comportamentos semelhantes. Ou seja, a tendência à igualdade foi reduzida (Gráfico 2).

Observando o Gráfico 2 e a Tabela 2, percebe-se que a taxa de crescimento do PIB per capita feminino tem, na média, comportamento muito semelhante à do PIB per capita masculino, com algumas exceções relevantes. Como já comentado, a taxa de variação do PIBFpc é superior nos primeiros anos da série, que as autoras reputam ser principalmente reflexo do aumento da escolaridade feminina. No último ano da série, a queda bastante acentuada e bem superior da taxa de crescimento do PIBFpc em relação 
ao PIBMpc coincide com um ano de crescimento negativo acentuado do PIB brasileiro. Não temos mais anos para comparar, mas esse dado parece indicar que as mulheres perdem emprego e renda mais rapidamente e em maior proporção que os homens nos momentos de crise ou depressão do PIB.

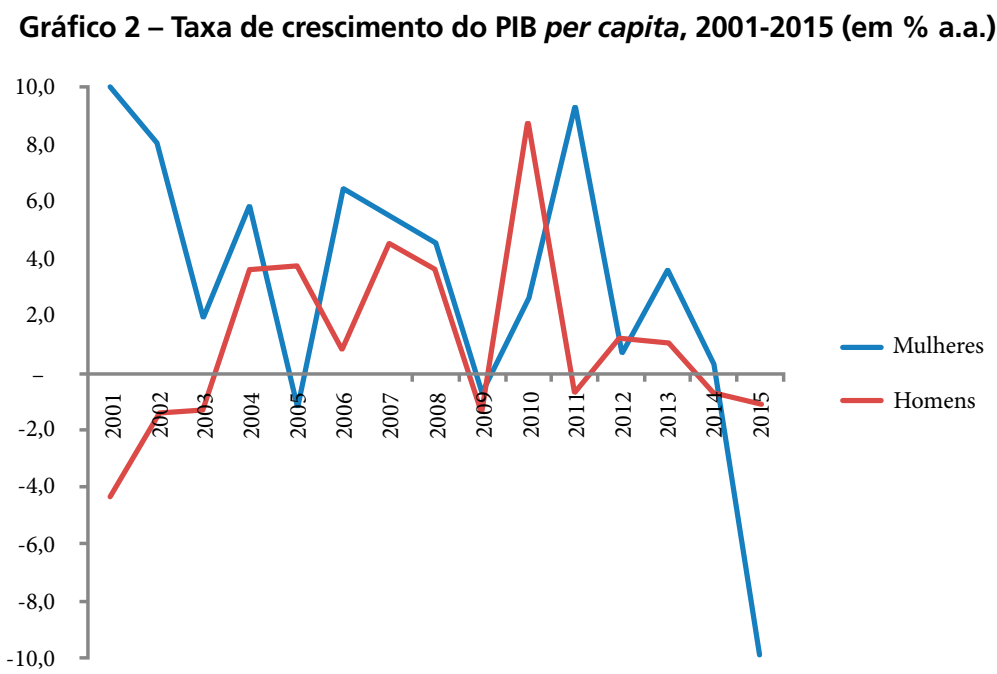

Fonte: Elaboração e estimativas próprias com base em dados de IBGE e IPEADATA, vários anos.

No período analisado, as maiores taxas de crescimento do PIB per capita feminino ocorreram em 2001, 2002 e 2011. Nesses 25 anos de análise, a relação entre o PIB per capita feminino e masculino tem aumentado, passando de 27,2\% em 1991 para $57,4 \%$ em 2015, ou seja, podemos concluir que os ganhos relativos de rendimento das mulheres brasileiras dobraram nesse período. Apesar desse ganho expressivo, as mulheres ainda têm um gap de PIB per capita em relação ao dos homens. Para cada R 1,00 de PIB per capita masculino, as mulheres auferem apenas R\$ 0,57 (Tabela 2 e Gráfico 1).

Em 1991, o PIB per capita brasileiro (PIBpc), a preços de 2015, foi de R $\$ 21.064,5$, sendo que o PIB per capita feminino (PIBFpc) foi de $\mathrm{R} \$ 9.081,9$ e o PIB per capita masculino (PIBMpc) foi de R \$33.353,8, ou seja, em um olhar de gênero, o PIB per capita feminino equivalia a 27,2\% do PIB per capita masculino. Em 2015, após os ganhos de renda das mulheres, como comentado anteriormente, e apesar da queda da taxa de crescimento do PIB naquele ano, observa-se uma melhoria na distribuição dos rendimentos, com as mulheres ampliando sua fatia no bolo nacional. O PIBpc em 2015 foi de R\$29.349,7, sendo o PIB per capita feminino de $\mathrm{R} \$ 21.486,6$ e o masculino de R\$ 37.410,7, ou seja, o PIBFpc chegou a 57,2\% do PIBMpc, um aumento de 30 pontos percentuais no período de 25 anos (Tabela 2 e Gráfico 3). 
Outro dado importante é que as linhas de tendência (Gráfico 3), que representam a evolução do PIB per capita feminino e masculino ao longo do período, são quase paralelas, o que mostra uma grande dificuldade para a eliminação da desigualdade da renda entre homens e mulheres no Brasil. Supondo que o PIB per capita de homens e mulheres cresce, a partir de 2015, à mesma taxa média de crescimento anual do período 2000-2015, ou seja, o PIBFpc crescendo a 3,1\% a.a. e o PIBMpc a 1,1\% a.a., seriam necessários mais 30 anos para que as mulheres alcançassem renda per capita média igual à dos homens no Brasil. No entanto, como não foram utilizados nesta análise os dados de 2016 e 2017, também com crescimento de PIB negativo, o resultado pode ser que o tempo necessário para a igualdade seja bem superior a 30 anos.

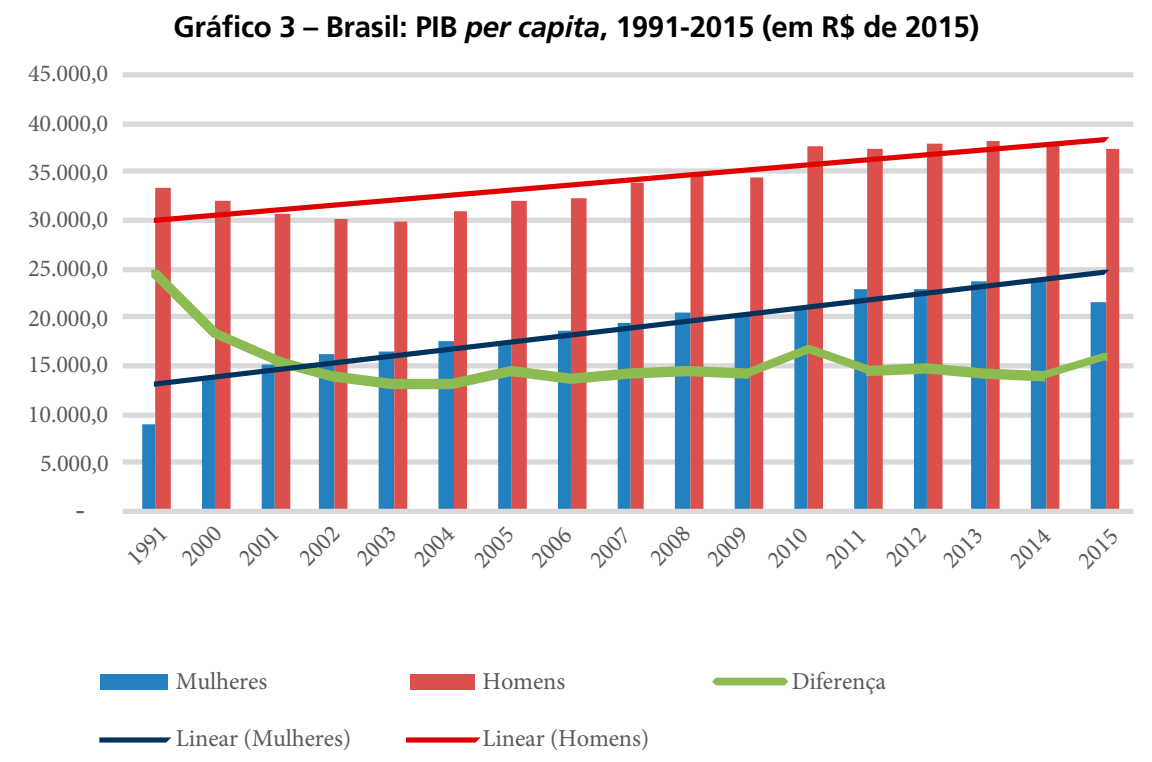

Fonte: Elaboração e estimativas próprias com base em dados de IBGE e IPEADATA, vários anos.

As mulheres são as principais responsáveis pelo trabalho de cuidados e afazeres domésticos no interior das famílias, porque culturalmente elas são vistas como naturalmente talhada para os cuidados. Mesmo quando elas têm trabalho remunerado ou mesmo quando ganham igual ao marido, elas dedicam mais tempo ao trabalho não remunerado que os homens (BITTMAN et al., 2003). Nesse sentido, a inserção da mulher no mercado de trabalho não é feita sem custos. Essa é uma das razões de as mulheres optarem por trabalhos de meio expediente ou com horário mais flexível, o que acarreta também menores salários e menor acesso às proteções trabalhistas. $\mathrm{Na}$ média, são mais frequentemente as mulheres nas famílias quem falta ao trabalho 
porque a criança ou um familiar idoso precisa de cuidado. Por ser quem socorre mais frequentemente os demais membros da família, ela é taxada no mercado de trabalho como menos confiável. A mulher também terá que se afastar do trabalho no período pós-parto e de amamentação. A diferença do tempo da licença para mulheres e homens deixa explícita essa determinação social e cultural e soma-se aos motivos preconceituosos em relação às mulheres e suas capacidades de competição no mercado de trabalho remunerado. A saída para que as mulheres possam competir de forma mais igualitária, melhorando sua remuneração e participação no mercado de trabalho, é, além de uma mudança cultural/social que deixe de ver as mulheres como pessoas de segunda linha, a ação de políticas públicas direcionadas especificamente a cuidados (ENGLAND; BUDIG; FOLBRE, 2002; FOLBRE, 2008).

A forma mais eficiente de se reduzir esse prazo e promover a igualdade entre gêneros é através da adoção de políticas públicas, como o aumento do número de creches e de escolas de tempo integral, e melhoria do transporte público com redução do tempo de deslocamento. Esses são alguns exemplos de políticas capazes de melhorar a competitividade da mulher no mercado de trabalho, por ser ela a maior responsável, na média, pelo cuidado dos filhos.

Como não foram adotadas medidas específicas de política pública que promovessem a redução da desigualdade de rendimento entre homens e mulheres no Brasil, pode-se concluir que a melhoria da renda per capita feminina se deveu ao crescimento da participação das mulheres no mercado de trabalho. As mulheres eram $40 \%$ da PEA nacional em 2000 e chegaram em 2015 a 44\%, ou seja, em 15 anos as mulheres elevaram em $10 \%$ sua participação no mercado de trabalho.

Soma-se a isso o aumento do nível de escolaridade das mulheres no período analisado, com crescimento médio superior ao dos homens, com destaque para a maior participação das mulheres com grau de escolaridade superior (MORANDI; MELO, 2019). Mesmo permanecendo a segregação de gênero na ocupação de postos de chefia e de gerência, a obtenção do diploma universitário possibilitou a elevação do rendimento, embora de forma não igualitária entre os sexos.

\section{CONSIDERAÇÕES FINAIS}

Este trabalho representa um exercício que desnuda a desigualdade da renda proveniente dos rendimentos do trabalho principal entre mulheres e homens no Brasil. O fio condutor do trabalho utiliza o indicador econômico mais importante para a mensuração das atividades econômicas, o PIB. Esse indicador, juntamente com a Renda Nacional, fornece informações fundamentais para a elaboração de políticas públicas, e, consequentemente, a omissão do valor gerado pelos afazeres domésticos e cuidados prestados às famílias do cálculo desses indicadores gera um viés nas análises macroeconômicas da economia brasileira e nas proposições de políticas públicas. 
As últimas recomendações da Organização Internacional do Trabalho (OIT) ampliaram o quadro conceitual de atividades para a categoria "trabalho" e incluíram não apenas o trabalho não remunerado, como também o trabalho voluntário em associações comunitárias e o cuidado das pessoas em situação de vulnerabilidade. Isso significa que há intenção política para uma avaliação mais cuidadosa dos indicadores de nível de qualidade de vida e de bem-estar das pessoas que vá além das medidas médias gerais já utilizadas, além de colaborar para o reconhecimento da luta das mulheres pela igualdade.

Estamos seguras de que, se os indicadores econômicos nacionais incorporassem o valor do trabalho não remunerado, as pessoas que o realizam seriam beneficiadas econômica e psicologicamente. Ao reconhecer e valorar a contribuição tão importante do trabalho não remunerado, a sociedade passa a tratar como preocupação de todos e todas a disponibilidade de tempo para os cuidados da vida e sua reprodução. Sem esses cuidados, o trabalho remunerado e a produção mercantil seriam prejudicados, porque não seriam possíveis de serem realizados nos moldes atuais. Os países em que os movimentos sociais foram mais fortes e eficientes e/ou as sociedades mais sensíveis lograram implementar medidas de maior proteção às pessoas, na forma de mais espaços públicos que oferecem serviços de cuidados e que liberam mães e pais, filhos/as e parentes de parte dos cuidados. Através das estimativas aqui apresentadas, que imputam uma dimensão das relações de gênero para o cálculo anual da riqueza per capita produzida no Brasil, pretendemos mostrar que um dos reflexos do não reconhecimento da importância do trabalho não remunerado é um salário menor para as mulheres no mercado de trabalho remunerado. Isso porque, de alguma forma, a sociedade reconhece que elas têm mais necessidade de dividir seu tempo entre casa, trabalho e lazer que os homens, menos responsáveis pela casa e pelos cuidados. A injustiça do não reconhecimento do trabalho não remunerado recai sobre as mulheres e os números aqui apresentados, mesmo que preliminares, mesmo que não exatos em termos estatísticos, já nos dão uma ideia da dimensão desse trabalho e do seu impacto negativo no cotidiano e na vida profissional das mulheres.

Elas não apenas têm salários menores, como obtêm menor fatia da renda nacional, na forma de menor PIB per capita, o que também se refletirá na renda das mulheres após a aposentadoria. Lembrando que uma porção importante de famílias no Brasil tem uma mulher como arrimo, o menor salário e menor PIB per capita feminino significa menor riqueza dessas famílias e reprodução da pobreza. Fazer valorar o trabalho das mulheres igual ao dos homens é questão de justiça social, de bem-estar econômico, de política de redistribuição de renda e, como não poderia deixar de ser, uma maior renda das mulheres e das famílias encabeçadas por mulheres geraria mais consumo, refletindo em maior PIB e maior nível de emprego na economia. Mulheres e homens seriam beneficiados como um todo. 
Reconhece-se a audácia do enfoque que as autoras propõem aos cânones da teoria econômica, ao elaborar esse indicador do PIB per capita por sexo e submetê-lo à apreciação de seus pares. A ousada hipótese proposta, no entanto, mostrou-se coerente com os dados oficiais relativos ao mercado de trabalho. Os números apresentados na partição do PIB per capita, que esta pesquisa elaborou, imprimem confiança às autoras para esperar outras contribuições que permitam que a teoria econômica avance no aprofundamento das relações de gênero no seio das reflexões econômicas.

Por último, cabe destacar que, ao longo desses anos, os padrões das relações de gênero na sociedade brasileira permaneceram quase inalterados no que se refere à divisão sexual do trabalho, e, infelizmente, os avanços sociais das mulheres no campo educacional e do trabalho não foram suficientes para construir a igualdade de rendimentos entre os gêneros. No entanto, é necessário afirmar seguramente que mais educação possibilitou a ida ao mercado de trabalho e a melhoria dos rendimentos femininos, e a análise feita por este estudo comprova que, ao longo dos anos analisados, as mulheres conquistaram ganhos significativos de PIB per capita relativo ao dos homens, passando de $27,2 \%$ do PIB per capita masculino, em 1991, para 57,4\% em 2015. Esse resultado é um reflexo e consequência direta do esforço individual das mulheres para conquistar espaço, muito mais do que de mudanças promovidas pela sociedade.

O exercício proposto por este estudo simboliza o reconhecimento de que o trabalho das mulheres foi sempre indispensável, e as estatísticas mostram que em todos os momentos as mulheres trabalharam e muito. E que a visibilização do trabalho feminino, seja remunerado ou não como trabalho profissional, é uma questão de justiça social.

\section{REFERÊNCIAS}

AGUIAR, N. (Org.). Gênero e ciências humanas: desafio às ciências desde a perspectiva das mulheres. Rio de Janeiro: Rosa dos Tempos; Record, 1997.

AMOSSÉ, T. As estatísticas nos estudos de gênero: um instrumento revelador? In: MARUANI, M. (Org.). Trabalho logo existo: perspectivas feministas. Rio de Janeiro: FGV, 2019. p. 41-52.

ARAÚJO, J. L.; MELO, H. P. Notas preliminares para o cálculo do PIB per capita por gênero. [S. l.; s. n.], 2004. Mimeo.

BECKER, G. Family economics and the macro behavior. American Economic Review, v. 78, n. 1, p. 1-13, 1988.

BITTMAN, M. et al. When does gender trump money? Bargaining and time in household work. American Journal of Sociology, v. 109, n. 1, p. 186-214, 2003.

BOSERUP, E. Woman's Role in Economic Development. New York: St Martin's Press; Crows Nest: George Allen \& Unwin, 1970. 
ENGLAND, P.; BUDIG, M.; FOLBRE, N. Wages of virtue: the relative pay of care work. Social Problems, v. 49, n. 4, p. 455-473, 2002.

FEIJÓ, C. A.; RAMOS, R. L. O. Contabilidade Social: a nova referência das Contas Nacionais do Brasil. Rio de Janeiro: Campus, 2008.

FOLBRE, N. Hearts and spades: paradigms of household economics. World Development, v. 14, n. 2, p. 245-255, 1986.

FOLBRE, N. Valuing children: rethinking the economics of the Family. Cambridge: Harvard University Press, 2008.

HAKIKI-TALAHITE, F. Pour une problemátique du procés de travail domestique. In: BARRERE-MAURISSON, M. A. Le sexe du travail: structures familiales et système productif. Grenoble: Presses Universitaires de Grenoble, 1984. p. 221-237.

IBGE - INSTITUTO BRASILEIRO DE GEOGRAFIA E ESTATÍSTICA. Pesquisa Nacional por Amostra de Domicílios: síntese de indicadores: 2015. Rio de Janeiro: IBGE, 2015. Disponível em: https://sidra.ibge.gov.br/pesquisa/pnad.

IBGE - INSTITUTO BRASILEIRO DE GEOGRAFIA E ESTATÍSTICA. Coordenação de Contas Nacionais. Sistema de Contas Nacionais: Brasil: ano de referência 2010. 3. ed. Rio de Janeiro: IBGE, 2016. (Relatórios Metodológicos, v. 24)

IBGE - INSTITUTO BRASILEIRO DE GEOGRAFIA E ESTATÍSTICA. Conta-satélite de saúde: Brasil: 2010-2015. Coordenação de Contas Nacionais. Rio de Janeiro: IBGE, 2017.

IPEADATA. Macroeconômico. Série do PIB a câmbio médio. Banco Central do Brasil, Boletim, Seção Atividade Econômica (Bacen / Boletim / Ativ. Ec.). [On-line] IPEADATA, 2018. Disponível em: http://ipeadata.gov.br/Default.aspx. Acesso em: 6 mar. 2021.

MACKINNON, C. A. Feminismo, Marxismo, Método e o Estado: uma agenda para a teoria. Direito \& Praxis, v. 7, n. 15, p. 798-837, 2016.

MELO, H. P. (Org.). Dossiê: A perspectiva feminista e os trabalhos sobre os usos do tempo. Revista Econômica, v. 12, n. 1, p. 7-10, 2010.

MELO, H. P.; CASTILHO, M. Trabalho reprodutivo no Brasil: quem faz? Revista de Economia Contemporânea, v. 13, n. 1, p. 135-158, 2009.

MELO, H. P.; CONSIDERA, C. M.; SABBATO, A. Dez anos de mensuração dos afazeres domésticos no Brasil. In: FONTOURA, N. et al. Uso do Tempo e Gênero. Rio de Janeiro: UERJ, 2016. p. 173-188.

MELO, H. P.; CONSIDERA, C. M.; SABBATO, A. Os afazeres domésticos contam. Texto para Discussão, UFF, n. 177, 2005.

MELO, H. P.; CONSIDERA, C. M.; SABBATO, A. Os afazeres domésticos contam! Economia e Sociedade, v. 16, n. 3, p. 435-454, 2007.

MELO, H. P.; MORANDI, L.; DWECK, R. H. PIB per capita na ótica de gênero: Brasil 1991 a 2015. Texto para Discussão, UFF, n.335, 2018.

MELO, H. P.; SERRANO, F. A mulher como objeto da teoria econômica. In: AGUIAR, N. (Org.). Gênero e ciências humanas: desafio às Ciências desde a perspectiva das mulheres. Rio de Janeiro: Rosa dos Tempos: Record, 1997. p. 137-159. 
MELO, H. P.; THOMÉ, D. Mulheres e poder, história, ideias, indicadores. Rio de Janeiro: FGV Editora, 2018.

MERON, M. Trabalho remunerado e trabalho doméstico na França: mudanças nos conceitos. In: ABREU, A. P.; HIRATA, H.; LOMBARDI, M. R. (Orgs.). Gênero e trabalho no Brasil e na França: perspectivas interseccionais. São Paulo: Boitempo, 2016.

MICHEL, A. Femmes, sexisme et sociétés. Paris: Presses Universitairess de France, 1977.

MORANDI, L.; MELO, H. P. Mujeres y educación em Brasil: uma mirada de género. In: PEREZ, T. G. (Coord.). La educación de las mujeres em Iberoamérica: analysis historico. Valencia: Tirant Humanidades, 2019. p. 719-758.

OAKLEY, A. Housewife. London: Penguin Books, 1974.

PICCHIO, A. Visibilidad analítica y política del trabajo de reproducción social. In: CARRASCO, C. (Org.). Mujeres y Economía: nuevas perspectivas para viejos y nuevos problemas. Barcelona: Icaria, 1999. p. 201-244.

SCOTT, J. Gênero: uma categoria útil para a análise histórica. Tradução: Christine Rufino Dabat, Maria Betânia Ávila. Recife: [s. n.], 1990. Disponível em: https://edisciplinas.usp.br/ pluginfile.php/185058/mod_resource/content/2/G\%C3\%AAnero-Joan\%20Scott.pdf. Acesso em: 7 jan. 2020.

SOARES, C.; MELO, H. P.; BANDEIRA, L. M. O trabalho das mulheres brasileiras: uma abordagem a partir dos censos demográficos de 1872 a 2010. In: ENCONTRO ANUAL DA ASSOCIAÇÃO BRASILEIRA DE ESTUdOS DE POPULAÇÃO, 19, 2014, São Pedro. Anais [...]. Belo Horizonte: ABEP, 2014. p. 1-20.

SOUZA, P. H. G. F. Uma história de desigualdade: a concentração de renda entre os ricos no Brasil 1926-2013. São Paulo: Hucitec: ANPOCS, 2018.

UN - UNITED NATIONS. The World's Women 2015. Trends and Statistics. New York: United Nations Statistics Division, United Nations, 2016. Disponível em: https://www.un.org/ development/desa/publications/the-worlds-women-2015.html. Acesso em: 6 mar. 2021.

VANDERLAC, L. La economia doméstica a la salsa mercantil... o las valoraciones monetarias del trabajo doméstico. In: BORDERÍAS, C.; CARRASCO, C.; ALEMANY, C. (Orgs.). Las mujeres y el trabajo: rupturas conceptuales. Barcelona: Icaria; Madrid: Fuhen, 1994. p. 151-208.

WALKER, K. E. Pour la reconnaissance sociale des tâches domestiques des femmes. Déclaration de l'Association Américaine d'Économie Domestique. In: MICHEL, A. Femmes, sexisme et sociétés. Paris: Presses Universitairess de France, 1977. p. 171-178. 